Published in final edited form as:

Adv Mater. 2015 October 7; 27(37): 5547-5552. doi:10.1002/adma.201502003.

\title{
Enzyme-Responsive Nanoparticles for Targeted Accumulation and Prolonged Retention in Heart Tissue after Myocardial Infarction
}

\author{
Mary M. Nguyen ${ }^{\dagger}$, \\ Department of Bioengineering, Sanford Consortium for Regenerative Medicine, University of \\ California, San Diego, La Jolla, CA 92093, USA
}

Andrea S. Carlini ${ }^{\dagger}$,

Department of Chemistry \& Biochemistry, University of California, San Diego, La Jolla, CA 92093, USA

\author{
Miao-Ping Chien, \\ Department of Chemistry \& Biochemistry, University of California, San Diego, La Jolla, CA 92093, \\ USA
}

\section{Sonya Sonnenberg,}

Department of Bioengineering, Sanford Consortium for Regenerative Medicine, University of California, San Diego, La Jolla, CA 92093, USA

\section{Colin Luo,}

Department of Medicine, University of California, San Diego, La Jolla, CA 92093, USA

\section{Rebecca L. Braden,}

Department of Bioengineering, Sanford Consortium for Regenerative Medicine, University of California, San Diego, La Jolla, CA 92093, USA

\section{Kent G. Osborn,}

Animal Care Program, University of California, San Diego, La Jolla, CA 92093, USA

\section{Yiwen Li,}

Department of Chemistry \& Biochemistry, niversity of California, San Diego, La Jolla, CA 92093, USA

\author{
Nathan C. Gianneschi [Prof.], and \\ Department of Chemistry \& Biochemistry, University of California, San Diego, La Jolla, CA 92093, \\ USA
}

\section{Karen L. Christman [Prof.]}

Department of Bioengineering, Sanford Consortium for Regenerative Medicine, University of California, San Diego, La Jolla, CA 92093, USA

\footnotetext{
Correspondence to: Nathan C. Gianneschi, ngianneschi@ucsd.edu; Karen L. Christman, christman@eng . ucsd.edu.

$\dagger$ These authors contributed equally to this work.

Supporting Information

Supporting Information, including nanoparticle synthesis and characterization, details of the in vitro aggregation study, and details of the in vivo studies, are available from the Wiley Online Library or from the author.
} 
Nathan C. Gianneschi: ngianneschi@ucsd.edu; Karen L. Christman: christman@eng.ucsd.edu

\section{Abstract}

Herein, we describe a method for targeting to and retaining intravenously (IV) injected nanoparticles at the site of acute myocardial infarction (MI) in a rat model. Enzyme-responsive peptide-polymer amphiphiles (PPAs) were prepared and assembled as spherical micellar nanoparticles. The resulting nanoparticles respond to matrix metalloproteineases (MMP-2 and MMP-9) that are upregulated in heart tissue post-myocardial infarction. The nanoparticles undergo a morphological transition from spherical-shaped, discrete materials to network-like assemblies when acted upon by MMPs. We show that $15-20 \mathrm{~nm}$, responsive nanoparticles can be injected IV, undergoing reaction with MMPs in the heart after MI, with the resulting assemblies remaining within the infarct for up to 28 days. The initial studies reported here set the stage for the development of targeting systems for therapeutic delivery for acute MI. Critically, with this development, injection of materials is possible via the IV route immediately following MI, resulting in targeted accumulation and long term retention at the site of MI.

\section{Keywords}

nanoparticle; enzyme-responsive; myocardial infarction; intravenous injection; MMP

Heart failure following a myocardial infarction (MI) continues to be one of the leading causes of death. ${ }^{[1]}$ Immediately after MI, there is an initial inflammatory response with cardiomyocyte death and degradation of the extracellular matrix. ${ }^{[2,3]}$ This results in negative left ventricular (LV) remodeling leading to wall thinning, LV dilation, and depressed cardiac function. ${ }^{[4]}$ Several experimental approaches have been examined to inhibit this negative remodeling process; one promising approach is the use of injectable biomaterials, ${ }^{[5]}$ which can be used as stand-alone scaffolds to encourage endogenous repair or for delivering therapeutics such as cells, growth factors, or small molecules. ${ }^{[5,6]}$ Ideally a therapeutic should be delivered in a minimally invasive procedure as acutely as possible to prevent continued cardiomyocyte apoptosis and initiation of negative LV remodeling. Local intramyocardial delivery of biomaterials to the injured myocardium can be performed minimally invasively via catheter when the material is designed appropriately; ${ }^{[6]}$ however, needle-based injection during the acute phase post-MI is unlikely to translate to the clinic given safety concerns with the weakened acute MI wall and unstable patient population. ${ }^{[6,7]}$

Nanoparticles are attractive for minimally invasive delivery because they may be administered via intravenous (IV) injection and target the heart through the enhanced permeability and retention (EPR) effect that is present in the acute stages of MI due to leaky vasculature. ${ }^{[8]}$ Nanoparticle systems are unique in that they may be prepared with relatively small diameters ranging from $6-200 \mathrm{~nm}$, making them ideal for systemic transport. Particles with diameters from 10-100 nm have demonstrated improved circulation times, ${ }^{[13,14]}$ and nanoparticles possessing diameters from $15-350 \mathrm{~nm}$ have been injected IV and delivered to the infarct via the leaky post-MI vasculature. ${ }^{[10-12]}$ However, spherical nanoparticles within these size ranges are often cleared from the target tissue within 24 hours. ${ }^{[12,16,17]}$ Targeted nanoparticle systems are likely to increase retention within the 
myocardium, but many of these studies lack long-term evaluation beyond a few hours to days. ${ }^{[11,16,18]}$ Both active targeting to the infarcted myocardium and retention of the material for periods longer than 1 week are current and significant challenges in developing nanoparticle delivery strategies to treat MI.

We present a novel approach for targeting the MI as well for achieving prolonged retention of a material in an acute MI via IV injection. The nanoparticles were designed to respond to enzymatic stimuli (matrix metalloproteinases, MMPs) present in the acute MI resulting in a morphological transition from discrete micellular nanoparticles into network-like scaffolds (Figure 1). The fluorescent nanoparticle is composed of brush peptide-polymer amphiphiles (PPAs $)^{[19]}$ based on a polynorbornene backbone with peptide sequences specific for recognition of MMP-2 and MMP-9 (methods and characterization provided in Supplemental Information). IV delivery allows the enzyme-responsive nanoparticles to freely circulate in the bloodstream until reaching the infarct through the leaky post-MI vasculature, ${ }^{[8]}$ where they assemble and remain within the injured site for up to 28 days post-injection. Previously, similar enzyme-responsive nanoparticles were shown to successfully accumulate after IV delivery in murine tumors that chronically overexpressed MMP-2 and MMP-9. ${ }^{[19]}$ For the MI application, the polymer design was modified to optimize net polymer amphiphilicity. We reduced the degree of polymerization of the hydrophilic block and degree of conjugation of hydrophilic peptide such that the hydrophilic weight fraction was 0.45 instead of 0.55 , which increased the responsiveness of the system (Figure S6) by decreasing the peptide brush density within formulated micelles of the same size. In this study, we demonstrate proof-of-concept that these enzyme-responsive nanoparticles target, assemble, and are retained in an acute MI, thereby providing a promising approach for delivery of therapeutics immediately post-MI and obviating the need for risky intramyocardial injections.

We hypothesized that enzyme-responsive nanoparticles could respond to the upregulation of MMP-2 and MMP-9 that occurs in an acute MI, ${ }^{[20]}$ creating a scaffold that would be retained in the tissue. In a previous report, super resolution fluorescence microscopy was used to detect a particle size increase from a similarly responsive particle system within tumor tissue. ${ }^{[21]}$ To first evaluate whether the aggregated particles would remain in the infarct over time, we pretreated responsive (containing $L$-amino acids) and nonresponsive (containing $D$-amino acids) particles with MMP-9 for 24 hours to cause pre-aggregation of the responsive particles in vitro, and then injected the resulting material into healthy rat myocardium (in vivo methods provided in Supplemental Information). The results indicated that pretreated, responsive particles remain in the tissue up to 7 days post-injection, while nonresponsive particles were cleared after 1 hour (Figure 2). These data suggest that responsive particles are activated by MMP-9 to induce a morphological change into an assembled scaffold, which is retained at the injection site. By contrast, nonresponsive particles remain inert in the presence of MMP-9 and are cleared quickly. Next, we evaluated our system in a rat MI model to determine whether upregulated MMPs in the infarct were sufficient to cause particle aggregation. Responsive and nonresponsive particles were delivered via intramyocardial injection 7 days post-MI, and rats were euthanized 6 days post-injection. Aggregation was observed in hearts that received responsive particles compared to minimal accumulation of the nonresponsive particles (Figure 3), demonstrating that the increased expression of MMPs post-MI activates the morphological transition of our 
responsive particles. The responsive particles were observed up to 6 days post-injection, suggesting that the network-like scaffold remains in the infarct zone over time, compared to the minimal aggregation observed for nonresponsive particles.

Finally, we tested whether the nanoparticle system could be delivered IV and accumulate in the infarct. Responsive and nonresponsive nanoparticles $(300 \mathrm{nmol})$ were injected into the tail vein of rats 24 hours post-MI (in vivo methods provided in Supplemental Information). After 2 days, greater accumulation was observed in the hearts of animals that received the responsive particles, compared to the nonresponsive particles (Figure 4). Responsive particles were found in the infarct and adjacent borderzone, but not in the remote, viable myocardium. This pattern of accumulation continued to be observed in the tissue at 7,14 , and 28 days post-injection, demonstrating that this unique targeting approach provides for long-term retention in the tissue. When responsive particles were injected into healthy, noninfarcted rats, no aggregates were observed in the heart (Figure 4). To test whether the leaky post-MI vasculature was necessary for particle accumulation in the infarct, we injected responsive particles (IV route) 30 days post-MI. The EPR effect, which occurs acutely post$\mathrm{MI},{ }^{[2,22]}$ is less prevalent over time. ${ }^{[8]}$ For example, in other studies, less accumulation of liposomes has been observed when injected IV 7 days post-MI compared to both 1 and 4 days post-MI. ${ }^{[10]}$ In our system, minimal accumulation was observed when delivered in the presence of a chronic MI (Supplemental Information, Figure S7), suggesting that the EPR effect is necessary for particles to initially enter the tissue. Other nanoparticle systems have exploited the EPR effect for passive targeting including polymeric micelles ${ }^{[23]}$, liposome based nanoparticles ${ }^{[24]}$, and vascular endothelial growth factor (VEGF)-encapsulated liposomes ${ }^{[25]}$. While these systems showed promise in treating MI by demonstrating increased cardiac function or decrease in infarct size compared to their saline or non-treated controls, they are limited by their lack of long-term retention. The MMP responsive nanoparticles reported here likewise use the EPR effect for initial passive targeting. However, in contrast, these particles undergo a morphological switch in response to upregulated MMPs, due to incorporation of the MMP-cleavable peptide sequence, which results in long-term retention (up to 28 days) at the site of infarction.

A therapeutic material should remain in the infarcted tissue for a prolonged period of time ( $>1$ week to several weeks) to adequately prevent negative LV remodeling. This places a substantial burden on nanoparticle design and delivery strategies. Surprisingly, only a limited number of studies have looked at long-term retention of nanoparticles, but of those that have, nanoparticles relying solely on passive targeting mechanisms (i.e. via the EPR effect) are rapidly cleared from target tissue. ${ }^{[2,17,26,27]}$ Nanoparticles relying on active targeting mechanisms involving receptor recognition, such as MMP-2 and MMP-9 targeting peptides, ${ }^{[28]}$ have demonstrated efficient targeting in ischemic zones and shown somewhat improved retention times from $24 \mathrm{hr}$ to 7 days. ${ }^{[17,27]}$ Despite these improvements, current receptor binding strategies to target ligands in the infarct post-MI are not sufficient for prolonged retention. ${ }^{[10,29]}$ Data for target tissue retention of receptor binding nanoparticles within other disease models (e.g. ischemic hindlimb or cancer) beyond hours or days is similarly lacking. ${ }^{[30]}$ Our results demonstrate that a localized morphology change from nanoscale spherical micelles to microscale network-like materials drastically enhances retention within the infarct as compared with non-responsive particles, providing a unique 
tactic for overcoming rapid tissue clearance. Unlike other systems, we utilize an active targeting mechanism reliant on the activity of an enzyme, rather than a receptor binding event. Furthermore, our system is maintained in the infarct zone as suggested by visualization of the rhodamine dye up to 28 days post-injection. Given that free dye would be rapidly cleared and that the nonresponsive particles also have the same tag, yet do not show the same degree of aggregation and retention, this suggests that fluorescently labeled aggregates remain in the tissue.

In addition to infarct targeting, off-site accumulation and safety are important to assess with any nanoparticle therapy. Histopathologic evaluation of heart sections showed expected inflammatory responses associated with MI remodeling. ${ }^{[2]}$ No differences were observed between infarcted myocardium containing aggregated particles and the time matched infarct controls, which received no injections. Furthermore, at 28 days post-injection, there was no observed difference in macrophage infiltration (as identified by CD68+ cells) compared to the infarct control (Supplemental Information, Figure S8). We also evaluated the biodistribution of responsive particles to satellite organs. Particles were observed in the liver, spleen, and lung, with minimal presence seen in the kidneys (Supplemental Information, Figure S9). The biodistribution of nanoparticles when delivered IV has been described for a number of different systems, and it is generally accepted that larger particles are internalized by the reticuloendothelelial system (RES), while smaller particles are more widely distributed in the body. ${ }^{[14,31-33]}$ Despite these observations, the toxicity and biodistribution of nanoparticles when delivered IV is not well understood. ${ }^{[32,34]}$ For example, similarly sized nanoparticles composed of silver, gold, and poly(ethylene glycol) have shown different distribution trends. ${ }^{[31,33]}$ Among polymeric nanoparticles, toxicity has been evidenced by acute liver inflammation and apoptosis. ${ }^{[31]}$ To assess the potential toxicity of our responsive particles, satellite organs from rats, 2 and 28 days post-IV injection ( 3 and 29 days post-MI, respectively) were evaluated and compared to those from both healthy and infarcted rats that received no injections (Supplemental Information Figure S10). Satellite organ histopathologic evaluation revealed essentially normal tissues. In addition, no signs of weight loss or changes in behavior were observed within both groups for up to 5 days postinjection and upon euthanasia 28 days post-injection. These results indicate that there were no signs of toxicity from these nanoparticles. It will however be important to perform more rigorous toxicity studies prior to translation. The responsive particles were fluorescently labeled for easy detection ex vivo; however, this label would not be necessary for human application. While ROMP polymers containing polynorbornene backbones have similarly shown to be non-toxic in the presence of mammalian cell lines, ${ }^{[35][36]}$ several additional toxicity and biocompatibility studies will be necessary to prove the safety of this polymer and nanoparticle formulations.

Early intervention of MI has the potential to slow or inhibit the progression of negative LV remodeling. To date, most therapeutic delivery strategies have involved intramyocardial biomaterial injections ${ }^{[7]}$, although translation to acute MI patients is unlikely given the increased risk of ventricular rupture immediately post-MI. ${ }^{[6,7]}$ One promising, minimally invasive strategy is the systemic injection of nanoparticles. However, many of the investigated systems lack long-term retention within the MI. ${ }^{[10,23,24]}$ The enzymeresponsive nanoparticles described here provide an efficient template for targeting the acute 
MI and remain in the infarct for up to 28 days post-injection. We have shown that the responsive nanoparticles are enzyme-responsive, accumulate due to upregulation of MMPs after MI, and are deliverable through both intramyocardial and IV injection. In summary, this unique approach constitutes a minimally invasive method for the delivery of a material scaffold to acutely infarcted myocardium, providing a promising approach for prolonged therapeutic delivery. Future studies will explore the conjugation of different small molecule or peptide therapeutics, and their efficacy in the heart balanced with potential side effects from off target nanoparticle retention.

\section{Supplementary Material}

Refer to Web version on PubMed Central for supplementary material.

\section{Acknowledgements}

The authors would like to thank Dr. Andrea Luthi and Jessica Ungerleider for their thoughtful revisions on this manuscript. The authors are also grateful for the support of a NIH Director's Transformative Research Award (HL117326), part of the NIH Common Fund. SS and ASC would like to thank the NSF for a Graduate Research Fellowship.

\section{References}

1. Mozaffarian D, Benjamin EJ, Go AS, Arnett DK, Blaha MJ, Cushman M, de Ferranti S, Despres JP, Fullerton HJ, Howard VJ, Huffman MD, Judd SE, Kissela BM, Lackland DT, Lichtman JH, Lisabeth LD, Liu S, Mackey RH, Matchar DB, McGuire DK, Mohler ER 3rd, Moy CS, Muntner P, Mussolino ME, Nasir K, Neumar RW, Nichol G, Palaniappan L, Pandey DK, Reeves MJ, Rodriguez CJ, Sorlie PD, Stein J, Towfighi A, Turan TN, Virani SS, Willey JZ, Woo D, Yeh RW, Turner MB. C. American Heart Association Statistics, S. Stroke Statistics. Circulation. 2015; 131:e29. [PubMed: 25520374]

2. Frangogiannis NG, Smith CW, Entman ML. Cardiovascular Research. 2002; 53:31. [PubMed: 11744011]

3. Dobaczewski M, Gonzalez-Quesada C, Frangogiannis NG. J Mol Cell Cardiol. 2010; 48:504. [PubMed: 19631653]

4. Sun Y, Weber KT. Cardiovascular Research. 2000; 46:250. [PubMed: 10773228] Mann DL. Circulation. 1999; 100:999. [PubMed: 10468532] Yang F, Liu YH, Yang XP, Xu J, Kapke A, Carretero OA. Exp Physiol. 2002; 87:547. [PubMed: 12481929]

5. Rane AA, Christman KL. JACC. 2011; 58:2615. [PubMed: 22152947]

6. Johnson TD, Christman KL. Expert Opinion on Drug Delivery. 2013; 10:59. [PubMed: 23140533]

7. Ungerleider JL, Christman KL. Stem Cells Transl Med. 2014; 3:1090. [PubMed: 25015641]

8. Horwitz LD, Kaufman D, Keller MW, Kong YO. Circulation. 1994; 90:2439. [PubMed: 7955201]

9. Prabhakar U, Maeda H, Jain RK, Sevick-Muraca EM, Zamboni W, Farokhzad OC, Barry ST, Gabizon A, Grodzinski P, Blakey DC. Cancer Res. 2013; 73:2412. [PubMed: 23423979]

10. Dvir T, Bauer M, Schroeder A, Tsui JH, Anderson DG, Langer R, Liao R, Kohane DS. Nano Lett. 2011; 11:4411. [PubMed: 21899318]

11. Won YW, McGinn AN, Lee M, Bull DA, Kim SW. Molecular Pharmaceutics. 2013; 10:378. [PubMed: 23214982]

12. Paulis LE, Geelen T, Kuhlmann MT, Coolen BF, Schaefers M, Nicolay K, Strijkers GJ. Journal of Controlled Release. 2012; 162:276. [PubMed: 22771978]

13. Longmire M, Choyke PL, Kobayashi H. Nanomedicine (London, England). 2008; 3:703.

14. Alexis F, Pridgen E, Molnar LK, Farokhzad OC. Mol. Pharmaceutics. 2008; 5:505.

15. Choi HS, Liu W, Misra P, Tanaka E, Zimmer JP, Ipe BI, Bawendi MG, Frangioni JV. Nature biotechnology. 2007; 25:1165. 
16. Suarez S, Almutairi A, Christman KL. Biomaterials Science. 2015; 3:564. [PubMed: 26146548]

17. Chang MY, Yang YJ, Chang CH, Tang ACL, Liao WY, Cheng FY, Yeh CS, Lai JJ, Stayton PS, Hsieh PCH. J Control Release. 2013; 170:287. [PubMed: 23665256]

18. Liu X, Chen Y, Li H, Huang N, Jin Q, Ren K, Ji J. ACS Nano. 2013; 7:6244. [PubMed: 23799860]

19. Chien M-P, Thompson MP, Barback CV, Ku T-H, Hall DJ, Gianneschi NC. Adv. Mater. Weinheim. 2013; 25:3599. [PubMed: 23712821]

20. Spinale FG. Physiol. Rev. 2007; 87:1285. [PubMed: 17928585]

21. Chien M-P, Carlini AS, Hu D, Barback CV, Rush AM, Hall DJ. JACS. 2013; 135:18710.

22. Galaup A, Gomez E, Souktani R, Durand M, Cazes A, Monnot C, Teillon J, Le Jan S, Bouleti C, Briois G, Philippe J, Pons S, Martin V, Assaly R, Bonnin P, Ratajczak P, Janin A, Thurston G, Valenzuela DM, Murphy AJ, Yancopoulos GD, Tissier R, Berdeaux A, Ghaleh B, Germain S. Circulation. 2012; 125:140. [PubMed: 22086875]

23. Lukyanov AN, Hartner WC, Torchilin VP. J Control Release. 2004; 94:187. [PubMed: 14684282]

24. Geelen T, Paulis LE, Coolen BF, Nicolay K, Strijkers GJ. Contrast Media Mol Imaging. 2013; 8:117. [PubMed: 23281284]

25. Scott RC, Rosano JM, Ivanov Z, Wang B, Chong PL-G, Issekutz AC, Crabbe DL, Kiani MF. Faseb Journal. 2009; 23:3361. [PubMed: 19535683]

26. Mizrahy S, Goldsmith M, Leviatan-Ben-Arye S, Kisin-Finfer E, Redy O, Srinivasan S, Shabat D, Godin B, Peer D. Nanoscale. 2014; 6:3742. [PubMed: 24569711] Zhong Y, Meng F, Deng C, Zhong Z. Biomacromolecules. 2014; 15:1955. [PubMed: 24798476]

27. Zhang C, Li C, Liu Y, Zhang J, Bao C, Liang S, Wang Q, Yang Y, Fu H, Wang K, Cui D. Adv. Funct. Mater. 2015; 25:1314.

28. Nguyen J, Sievers R, Motion JP, Kivimae S, Fang Q, Lee RJ. Mol Pharm. 2015; 12:1150. [PubMed: 25642730]

29. Wang Y, Lin T, Zhang W, Jiang Y, Jin H, He H, Yang VC, Chen Y, Huang Y. Theranostics. 2015; 5:787. [PubMed: 26000052] Scott RC, Wang B, Nallamothu R, Pattillo CB, Perez-Liz G, Issekutz A, Del Valle L, Wood GC, Kiani MF. Biotechnol. Bioeng. 2007; 96:795. [PubMed: 17051598] Yan K-J, Chen P, Wu J, Sun L, Sung H-W, Weisel RD, Xie J, Li R-K. Biomaterials. 2014; 35:1063. [PubMed: 24169002]

30. Wang Y, Zhou K, Huang G, Hensley C, Huang X, Ma X, Zhao T, Sumer BD, DeBerardinis RJ, Gao J. Nat Mater. 2014; 13:204. [PubMed: 24317187] Kim J, Cao L, Shvartsman D, Silva EA, Mooney DJ. Nano Lett. 2011; 11:694. [PubMed: 21192718] Mizrahy S, Goldsmith M, LeviatanBen-Arye S, Kisin-Finfer E, Redy O, Srinivasan S, Shabat D, Godin B, Peer D. Nanoscale. 2014; 6:3742. [PubMed: 24569711] Arosio P, Orsini F, Piras AM, Sandreschi S, Chiellini F, Corti M, Masa M, Muckova M, Schmidtova L, Ravagli C, Baldi G, Nicolato E, Conti G, Marzola P, Lascialfari A. RSC Advances. 2015; 5:39760.

31. Cho W-S, Cho M, Jeong J, Choi M, Cho H-Y, Han BS, Kim SH, Kim HO, Lim YT, Chung BH, Jeong J. Toxicology and Applied Pharmacology. 2009; 236:16. [PubMed: 19162059]

32. Johnston HJ, Hutchison G, Christensen FM, Peters S, Hankin S, Stone V. Critical Reviews in Toxicology. 2010; 40:328. [PubMed: 20128631]

33. Lankveld DPK, Oomen AG, Krystek P, Neigh A, Troost-de Jong A, Noorlander CW, Van Eijkeren JCH, Geertsma RE, De Jong WH. Biomaterials. 2010; 31:8350. [PubMed: 20684985] Sonavane G, Tomoda K, Makino K. Colloids and Surfaces B-Biointerfaces. 2008; 66:274.

34. Fischer HC, Chan WCW. Current Opinion in Biotechnology. 2007; 18:565. [PubMed: 18160274]

35. Gestwicki JE, Strong LE, Cairo CW, Boehm FJ, Kiessling LL. Chemistry \& Biology. 2002; 9:163. [PubMed: 11880031]

36. Kolonko EM, Pontrello JK, Mangold SL, Kiessling LL. J Am Chem Soc. 2009; 131:7327. [PubMed: 19469577] 

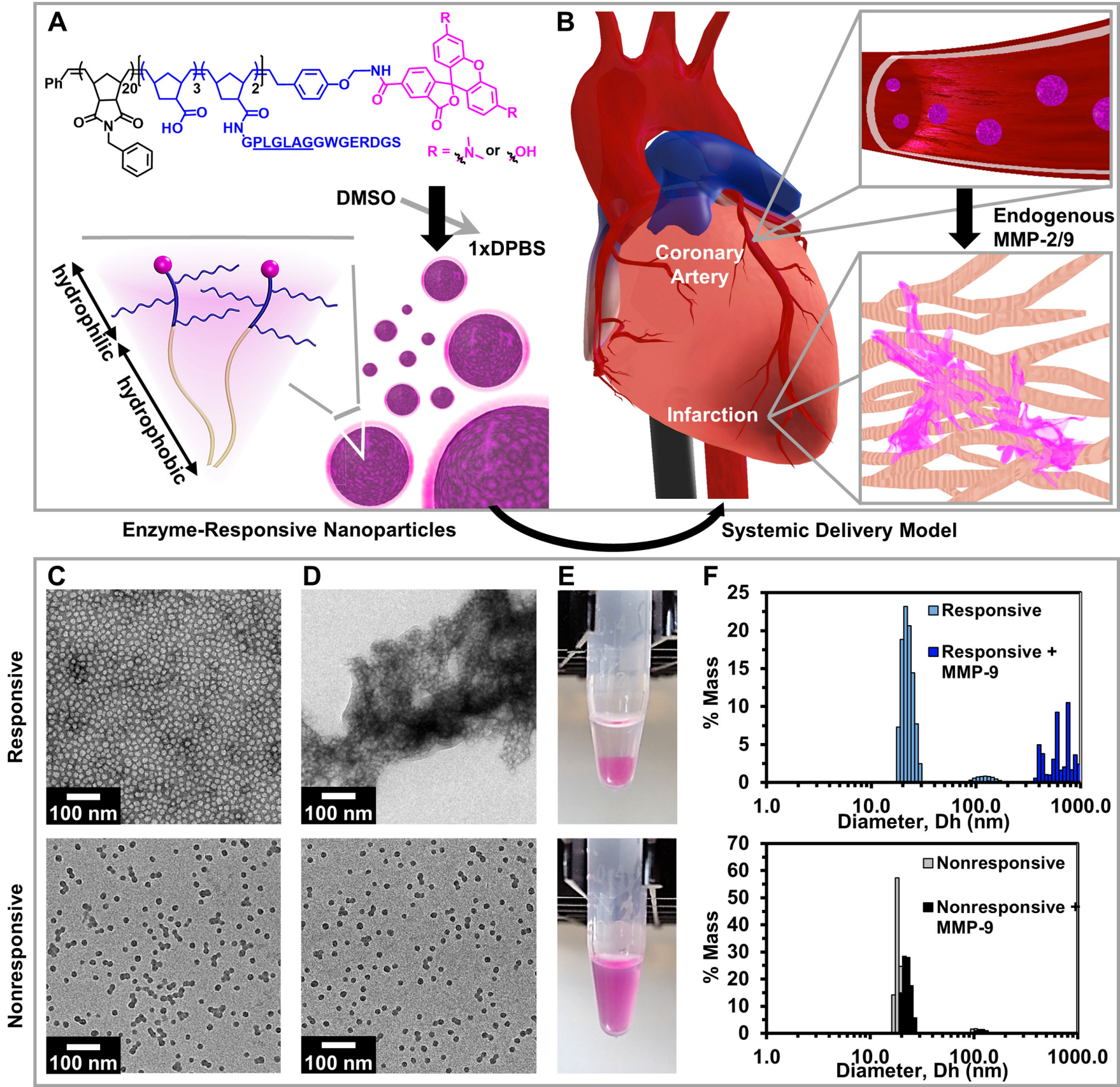

In-Vitro Responsiveness Model

Figure 1. Responsive nanoparticles target, accumulate, and are retained within an acute myocardial infarction due to enzyme-induced aggregation

(A) Diagram of a dye-labeled brush peptide-polymer amphiphile (PPA) containing an MMP-2 and MMP-9 specific recognition sequence, shown underlined. PPAs self-assemble into nanoparticles through hydrophobic-hydrophilic interactions when dialyzed into aqueous buffer. (B) Schematic of nanoparticles freely circulating in the bloodstream (not to scale) upon systemic delivery. Nanoparticles enter the infarct tissue through the leaky acute MI vasculature, and upregulated MMPs within the infarct induce the formation of an aggregatelike scaffold. (C) In vitro, responsive (top) and nonresponsive (bottom) nanoparticles are 
monodisperse micelles with diameters of 15-20 nm, and (D) upon activation, only responsive nanoparticles form an aggregate-like scaffold. (E) Corresponding images of nanoparticle solutions following activation. (F) Dynamic light scattering of nanoparticles before and after MMP activation. 


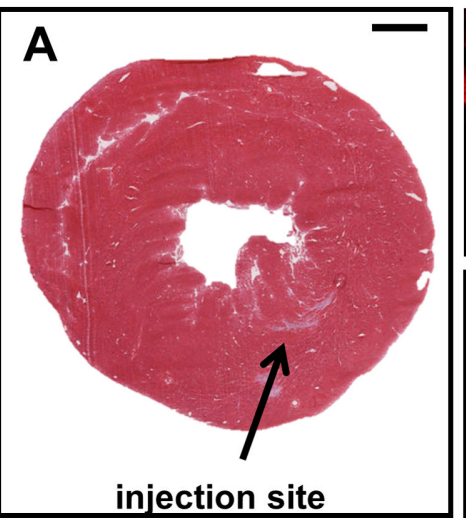

$1 \mathrm{~min}$

$1 \mathrm{hr}$

\section{B}
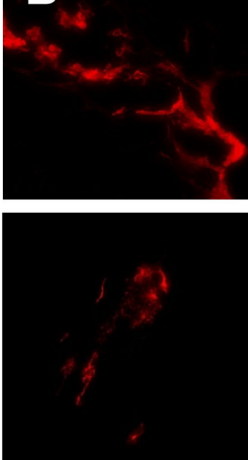
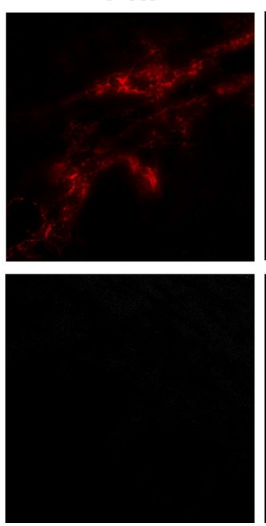

1 day
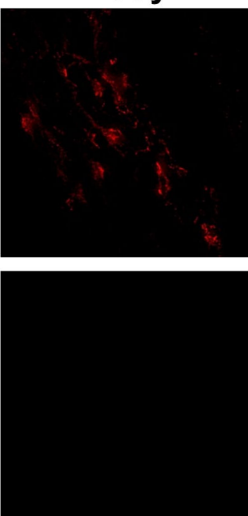

2 day
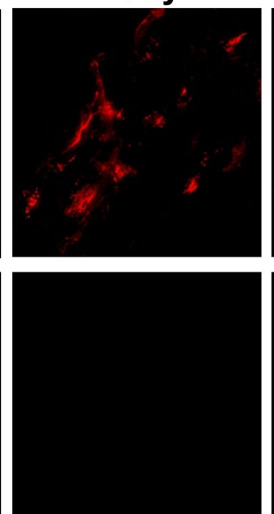

7 day

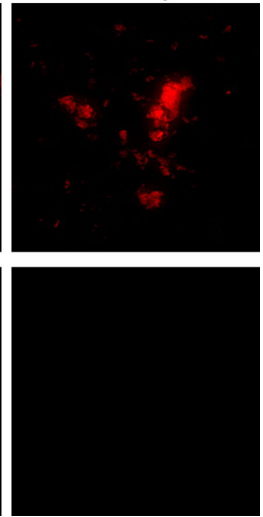

Figure 2. Retention of MMP pretreated responsive nanoparticles and clearance of nonresponsive nanoparticles in healthy myocardium

MMP pretreated particles were injected into healthy rat myocardium (A) and tissue was evaluated 1 minute, 1 hour, 1 day, 2 days, and 7 days post-injection for presence of the fluorescent aggregates (B). Rhodamine labeled, responsive particles (B, top row) were observed at the site of injection up to 7 days post-injection, while the nonresponsive particles (B, bottom row) were cleared after 1 hour. Scale bar: $1 \mathrm{~mm}$ (A); $50 \mu \mathrm{m}$ (B). 

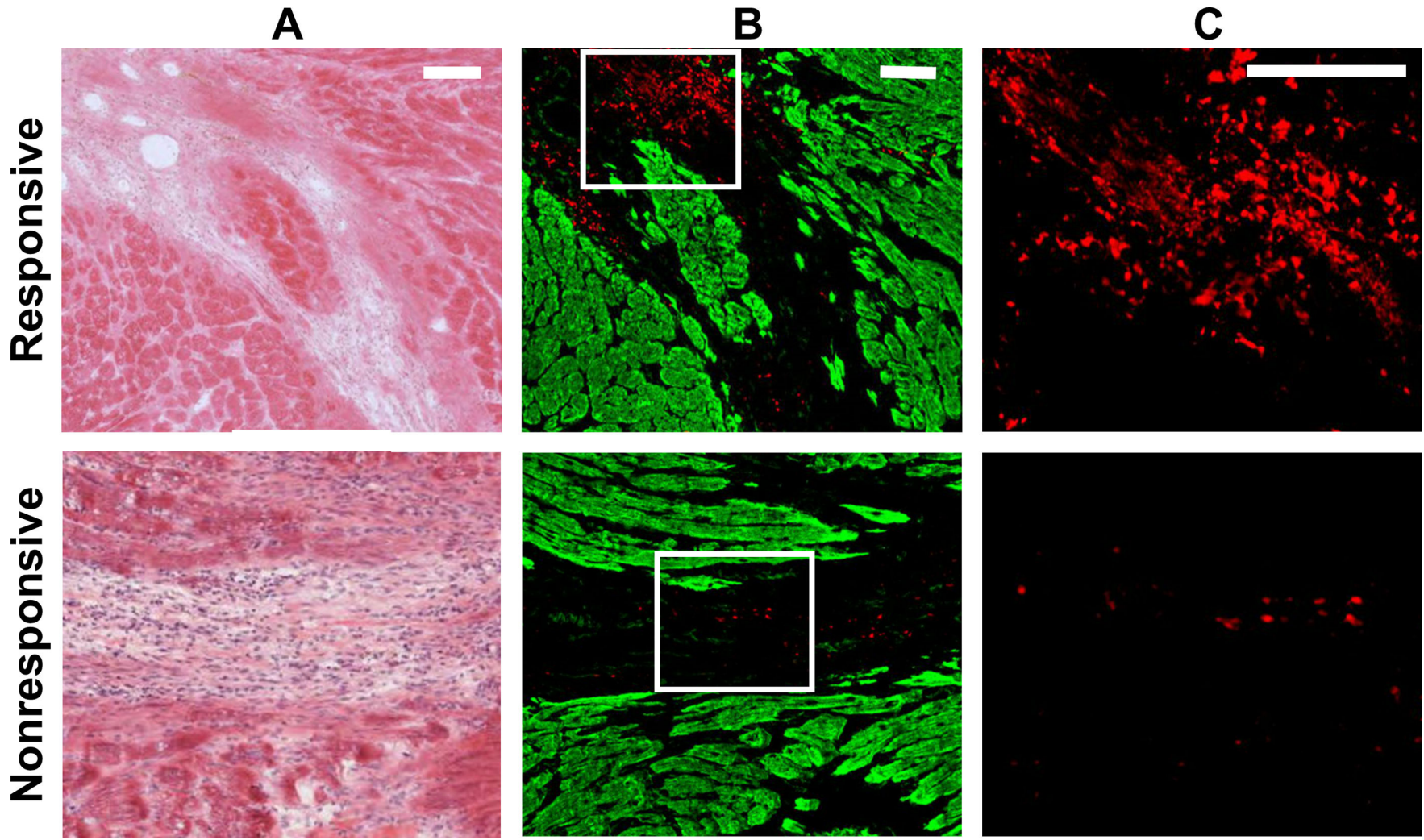

Figure 3. Retention of responsive nanoparticles upon localized delivery

Particles were injected intramyocardially 7 days post-MI and assessed 6 days post-injection.

$\mathrm{H} \& \mathrm{E}$ images display the infarct area in $\mathrm{A}$, and neighboring fluorescent sections are shown in

B. Particles are shown in red and myocardium, which was labeled with an anti-a-actinin antibody, is shown in green. Selected regions from B (white outline) were magnified to highlight particle aggregation in C. Scale bar: $100 \mu \mathrm{m}$. 
A
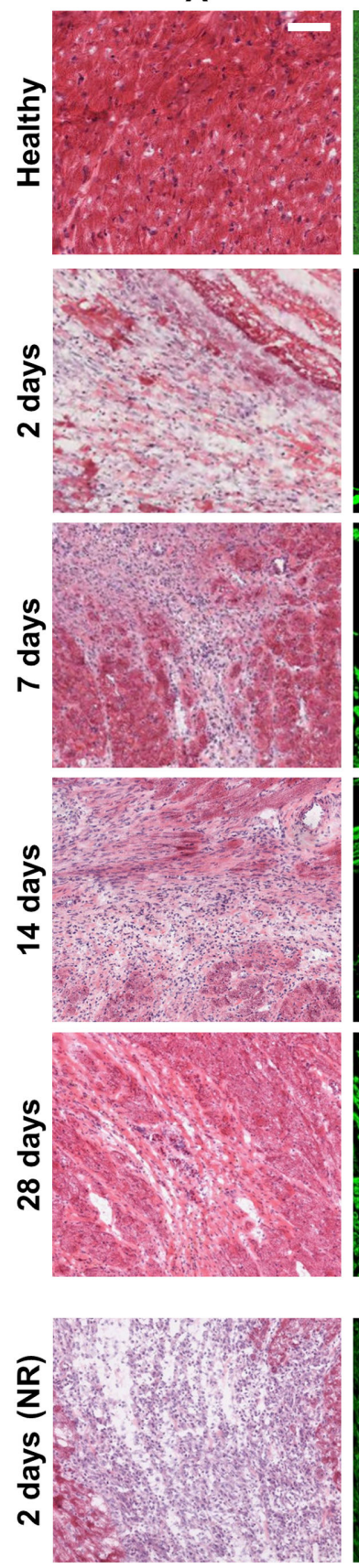

B
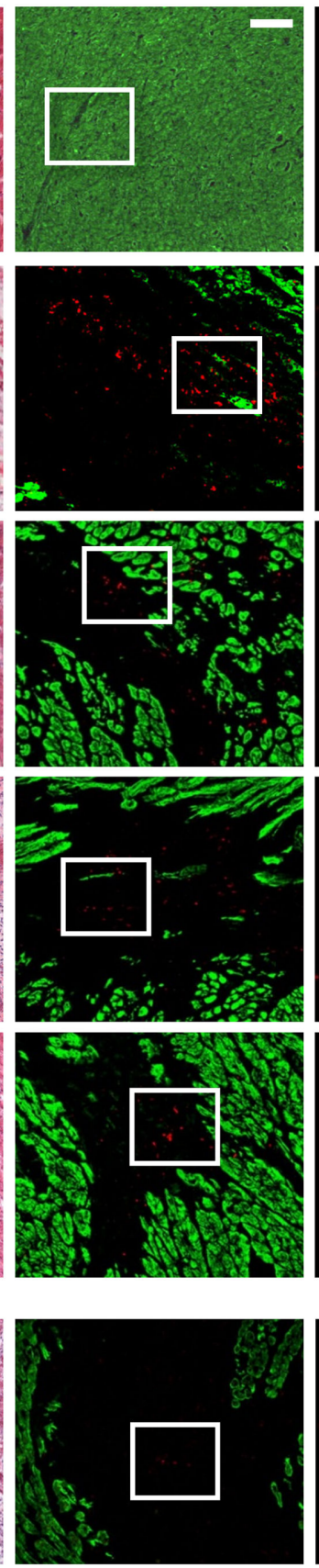

C
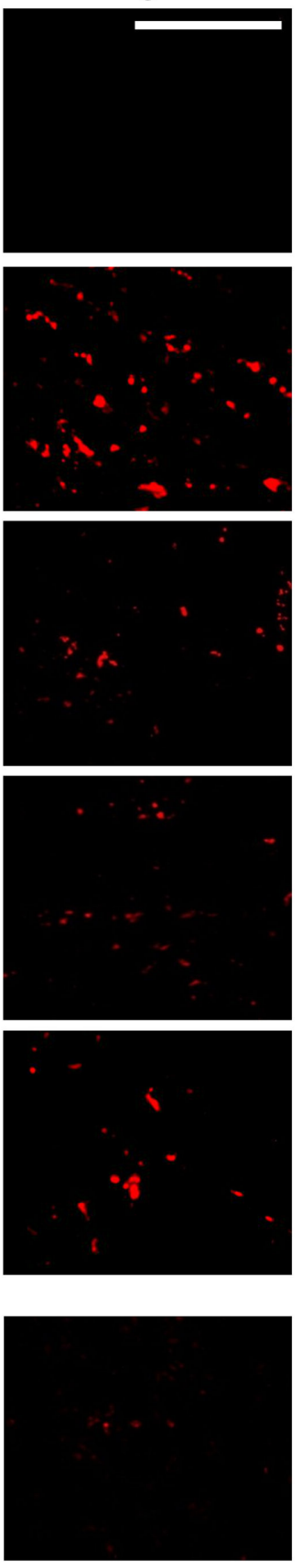

Figure 4. Retention of IV delivered nanoparticles with the infarct

H\&E images are shown in A, and neighboring fluorescent sections are shown in B. Particles are shown in red and myocardium, which was labeled with an anti-a-actinin antibody, is shown in green. Selected magnified regions from B (white outline) are shown in C. In the absence of an infarct, IV injected responsive particles do not accumulate in healthy myocardium. Very few nonresponsive particles (NR) particles, which were IV injected 24 hours post-MI, were observed in the infarct 2 days post-injection. In contrast, aggregates of 
responsive particles were observed in the infarct 2, 7, 14, or 28 days post-injection. Scale bar: $100 \mu \mathrm{m}$. 